\title{
Clinical efficacy of recombinant human latrophilin 3 antibody in the treatment of pediatric asthma
}

\author{
MAOHUA LIU ${ }^{1}$, JINGXIU ZHANG ${ }^{2}$ and CHENGJUN LIU ${ }^{1}$ \\ Departments of ${ }^{1}$ Pediatric Internal Medicine Ward 1, and ${ }^{2}$ Pediatric Internal Medicine Ward 3, \\ Yishui Central Hospital of Linyi, Linyi, Shandong 276400, P.R. China
}

Received August 18, 2016; Accepted May 19, 2017

DOI: $10.3892 /$ etm.2017.5376

\begin{abstract}
Pediatric asthma is a chronic pulmonary inflammatory disease featuring hypersecretion of mucus and inflammation in the airway, resulting in dysfunction of the airway smooth muscle. Previous evidence demonstrated that latrophilins, a novel family of receptors, present a beneficial effect on airway smooth muscle cells. In the present study, the therapeutic effects of recombinant human latrophilin 3 (rhLPHN3) antibody (Ab) in patients with pediatric asthma were investigated, and the molecular mechanism underlying the function of LPHN3 in the treatment of asthma in clinical practice was examined. A total of 342 pediatric asthma cases were recruited and randomly divided into three groups, receiving treatment with rhLPHN3 $\mathrm{Ab}(\mathrm{n}=134)$, salbutamol $(n=108)$ or montelukast $(n=100)$ by nasal aerosolization. Each group received the respective clinically tested dose for 16 weeks. Inflammatory factors interleukin (IL)-10, IL-17, IL-4, matrix metallopeptidase-9 (MMP-9), interferon- $\gamma$ (IFN- $\gamma$ ) and transforming growth factor- $\beta$ (TGF- $\beta$ ) levels in peripheral blood mononuclear cells were analyzed prior to and post treatment. The clinical outcomes revealed that pathological alterations were significantly improved following treatment with rhLPHN3 Ab for patients with pediatric asthma when compared with those receiving salbutamol and montelukast. It was also observed that rhLPHN3 Ab downregulated the plasma concentration levels of IL-10, IL-17, IL-4 and MMP-9, and upregulated IFN- $\gamma$ and TGF- $\beta$ levels in the three groups. In addition, clinical data demonstrated that rhLPHN3 Ab significantly promoted E-selectin and mucin 5AC expression, as well as improved the activation of nuclear factor (NF)- $\kappa \mathrm{B}$ p65 DNA binding activity and the phosphorylation levels of protein kinase A. Furthermore, rhLPHN3 Ab markedly improved adhesion and proliferation of airway smooth muscle cells, which led to promotion of the contraction of these cells.
\end{abstract}

Correspondence to: Dr Maohua Liu, Department of Pediatric Internal Medicine Ward 1, Yishui Central Hospital of Linyi, 17 JianKang Road, Linyi, Shandong 276400, P.R. China

E-mail: maohualiu@163.com

Key words: pediatric asthma, latrophilin 3, inflammation, $\mathrm{NF}-\kappa \mathrm{B}$, airway smooth muscle cells
In conclusion, these clinical data suggest that rhLPHN3 Ab serves an important role in the inhibition of inflammatory mediators through downregulation of $\mathrm{NF}-\kappa \mathrm{B}$ signaling pathway, which contributes to airway remodeling and bronchodilation in patients with pediatric asthma.

\section{Introduction}

Asthma is a chronic inflammatory disorder that affects $>300$ million people annually worldwide (1), and the worldwide incidence of pediatric asthma is currently increasing. Asthma is known to be a heterogeneous pulmonary disease characterized by chronic airway inflammation, leading to respiratory swelling and dyspnea (2-4). It has been demonstrated that mast cells, eosinophil granulocytes, cytokines and $\mathrm{T}$ cells serve essential roles in the initiation and progression of pediatric asthma $(5,6)$. Previous studies have also indicated that the inflammatory factors matrix metalloproteinase-9 (MMP-9) and transforming growth factor- $\beta$ (TGF- $\beta$ ) induced by immunocytes are closely correlated with airway inflammation and airway remodeling $(7,8)$.

In recent years, several studies have observed that the incidence of pediatric asthma presents an increasing trend according to clinical investigation $(9,10)$. Pediatric asthma was reported as the most common chronic respiratory disease in children, and this disease deleteriously impacts all aspects of systemic function (11). In addition, it has been suggested that patients with pediatric asthma exhibit behavioral and psychological problems that contribute to the risk for functional impairments and communication difficulties (12). Furthermore, environmental factors have been regarded as one of the main preventable contributors for the epidemiology of pediatric asthma (13). Notably, although various treatments have been proposed for pediatric asthma, numerous patients remain refractory under current clinical therapies. Therefore, novel and efficient treatments need to be urgently identified for patients with pediatric asthma.

Latrophilin agents, a novel family of receptors, have been reported to present beneficial effects on airway smooth muscle cells by regulating airway smooth muscle cell adhesion, proliferation and contraction (14). However, their physiological function remains unclear (15). Therefore, the present clinical trial hypothesized that recombinant human latrophilin 3 antibody (rhLPHN3Ab) may exert a beneficial effect on the 
recovery of patients with pediatric asthma due to its efficacy on the improvement of airway smooth muscle cell contraction, determined by forced expiratory volume (FEV), forced vital capacity (FVC) and peak expiratory flow (PEF).

Several signaling pathways involved in the initiation and development of pediatric asthma have been proposed, including $\mathrm{c}$-Jun $\mathrm{N}$-terminal kinase, tumor necrosis factor- $\alpha$ $(\mathrm{TNF}-\alpha)$, protein kinase A (PKA)/nuclear factor- $\kappa \mathrm{B}$ (NF-kB), MAP kinase-interacting serine/threonine-protein kinase 1 /eukaryotic initiation factor $4 \mathrm{E}$, extracellular signal-regulated kinase (ERK)1/2 and receptor for advanced glycation end products/ERK pathways (16-18). However, the mechanism(s) of rhLPHN3-mediated signaling pathway has not been reported in previous studies.

In the present study, the efficacy and underlying mechanism of LPHN3 in the treatment of pediatric asthma was investigated. It was observed that rhLPHN3 Ab decreased the expression levels of inflammatory mediators, and contributed to airway remodeling and bronchodilation through the PKA-induced NF- $\mathrm{KB}$ signaling pathway. Notably, the results indicated that rhLPHN3 Ab was associated with increased expression of E-selectin and mucin 5AC (MUC5AC). Given the clinical outcomes of the patients in the current study, rhLPHN3 Ab may be a potential agent for future application in the treatment of pediatric asthma.

\section{Materials and methods}

Ethics statement. This phase-I study (no. YSCOHLY20110812R1) was conducted between August 2011 and June 2015, in strict accordance with the recommendations and guidelines of the Yishui Central Hospital of Linyi (Linyi, China). This study was approved by the ethics committee of Yishui Central Hospital of Linyi. All patients and their guardians were required to review trial protocols and amendments, and provided informed consent prior to participation.

Patients and treatments. A total of 342 children with capillary bronchitis and asthma (age, 4-11-years-old) were recruited into the present study, and the 22-item sinonasal outcome test (SNOT-22) and Lund-Kennedy endoscopy scores (LKES) were used to evaluate the status of pediatric asthma (19). Patients were subjected to rhLPHN3, salbutamol or montelukast once a day in a double-blind trial at Yishui Central Hospital of Linyi. No others clinical syndromes were observed in this analysis. All children were instructed to wash their mouths thoroughly with normal saline before treatment. The children were randomly divided into three groups and received treatment with salbutamol (12 mg/day; Tianjin Lisheng Pharmaceutical Co., Ltd., Tianjin, China), montelukast (12 mg/day; Hangzhou MSD Pharmaceutical Co., Ltd., Hangzhou, China) or rhLPHN3 Ab (1:100 dilution with $0.9 \% \mathrm{NaCl}, 12 \mathrm{mg} /$ day; cat. no. BA7210, Boao Biological Pharmaceutical Co., Ltd., Tianjin, China) by nasal aerosolization for a total of 16 weeks.

Study design. Double-blind investigation was conducted at two time points: At the baseline stage, and at 16 weeks of treatment for patients with pediatric asthma. The patients continued treatment with the dose of salbutamol (12 mg/day), montelukast (12 mg/day) or rhLPHN3 Ab (12 mg/day) during the maintenance period.

Reverse transcription-quantitative polymerase chain reaction $(R T-q P C R)$. Total mRNA from airway smooth muscle cells (cells obtained by primary culture of smooth muscle tissue) was isolated using an mRNeasy Extraction kit (Qiagen, Inc., Valencia, CA, USA). Extracted mRNA ( $1 \mu \mathrm{g})$ was transcribed into cDNA using a reverse transcription kit (Qiagen, Inc.). The cDNA (10 ng) was used for qPCR using the SYBR Green Master mix system (Bio-Rad Laboratories, Inc., Hercules, CA, USA). All the forward and reverse primers for E-selectin and MUC5AC were synthesized by Invitrogen (Thermo Fisher Scientific, Inc.): E-selectin, forward 5'-CATTGGAGAGAA AGGAAAGTGTG-3' and reverse 5'-GCTTGCATGTACGAA GAGGAT-3'; MUC5AC, forward 5'-TCCAACTACTACCAA GAACTGAA-3' and reverse 5'-CAAGGAAATAGACGA TAGCCAA-3'; $\beta$-actin, forward 5'-GTGGGCGCCCAGGCA CCA-3' and reverse 5'-CTCCTTAATGTCACGCACGAT TT-3'. PCR amplification followed preliminary denaturation at $94^{\circ} \mathrm{C}$ for $2 \mathrm{~min}$, followed by 38 cycles of $95^{\circ} \mathrm{C}$ for $30 \mathrm{sec}$, annealing temperature reduced to $62^{\circ} \mathrm{C}$ for $30 \mathrm{sec}$ and $72^{\circ} \mathrm{C}$ for $10 \mathrm{~min}$ by volume of $20 \mu \mathrm{l}$ containing $50 \mathrm{ng}$ of genomic DNA, $200 \mu \mathrm{M}$ dNTP, 2.5 units of Taq DNA polymerase, and $200 \mu \mathrm{M}$ primers. Relative mRNA expression changes were calculated by $2^{-\Delta \Delta \mathrm{Cq}}(20)$.

Western blot analysis. Airway smooth muscle cells were isolated from pediatric asthma patients by primary culture of smooth muscle tissue and homogenized in lysate buffer containing protease-inhibitor (Invitrogen; Thermo Fisher Scientific, Inc.), then centrifuged at 7,104 $\mathrm{xg}$ at $4^{\circ} \mathrm{C}$ for $10 \mathrm{~min}$. Supernatants were collected and the protein concentration was detected using a Bio-Rad protein assay kit (cat. no. 500-0002; Bio-Rad Laboratories, Inc.) Protein $(30 \mu \mathrm{g})$ was separated by $10 \%$ SDS-PAGE assays followed by transference onto polyvinylidene difluoride membranes. The membranes were blocked in Tris-buffered saline buffer $(50 \mathrm{mmol} / \mathrm{l} \mathrm{NaCl}, 10 \mathrm{mmol} / \mathrm{l}$ Tris, $\mathrm{pH}$ 7.4) containing 5\% nonfat milk for $2 \mathrm{~h}$ at room temperature as previously described (20). For western blotting, the following rabbit anti-human primary antibodies were used: pPKA (cat. no. 14270-1-AP, 1:1,000, Proteintech) and $\beta$-actin (cat. no. 66009-1-Ig, 1:5,000, Proteintech). Primary antibodies were incubated overnight at $4^{\circ} \mathrm{C}$. Membranes were then incubated with secondary antibodies (cat. no. 4410, 1:1,000, Cell Signaling Technology) for $24 \mathrm{~h}$ at $4^{\circ} \mathrm{C}$. The results were visualized using an enhanced chemiluminescence detection system (Thermo Fisher Scientific, Inc.). BandScan 5.0 software (Glyko, Inc., Novato, CA, USA) was used for the quantification of proteins following western blot analysis.

$N F-\kappa B$ activation. Airway smooth muscle cells were collected and lysed by three freeze-thaw steps in $200 \mu 1$ of $0.25 \mathrm{M}$ Tris-HCl ( $\mathrm{pH}$ 7.9) plus $1 \mathrm{mM}$ dithiothreitol. Cell extracts were clarified in a microcentrifuge (7,104 x g), and $20 \mu \mathrm{l}$ of each extract was incubated with $350 \mu$ l of reaction buffer A [ $25 \mathrm{mM}$ glycyl-glycine (pH 7.8), 5 mM ATP (pH 7.5), 4 mM EGTA (pH 8.0), $15 \mathrm{mM} \mathrm{MgSO} 4]$ and then mixed with $100 \mu 10.25 \mathrm{mM}$ luciferin (Sigma-Aldrich; Merck KGaA) in reaction buffer A. A TD-20/20 luminometer (Turner Designs, Sunnyvale, CA, 
Table I. Characteristics of study population.

\begin{tabular}{lccc}
\hline Characteristic & Salbutamol & Montelukast & rhLPHN3 Ab \\
\hline No. of patients, & $134(39.2)$ & $108(31.6)$ & $100(29.2)$ \\
n (\%) & & & \\
Gender, $\mathrm{n}$ & & & \\
Male & 60 & 58 & 46 \\
Female & 74 & 50 & 54 \\
Mean age, years & $6.5 \pm 2.2$ & $6.6 \pm 2.8$ & $6.8 \pm 2.0$ \\
BMI & $16.8 \pm 3.4$ & $17.4 \pm 2.6$ & $17.2 \pm 3.0$ \\
SNOT-22 & $30.1 \pm 4.8$ & $32.2 \pm 5.6$ & $31.5 \pm 4.6$ \\
LKES & $8.2 \pm 2.5$ & $7.6 \pm 3.1$ & $8.3 \pm 1.9$ \\
FVC, 1 & $1.52 \pm 2.1$ & $1.47 \pm 2.6$ & $1.49 \pm 2.4$ \\
PEF, $\%$ & $68.4 \pm 7.8$ & $66.5 \pm 9.5$ & $67.2 \pm 8.6$ \\
FEV, \% & $65.2 \pm 6.2$ & $64.7 \pm 7.6$ & $66.2 \pm 8.1$ \\
\hline
\end{tabular}

BMI, body mass index; SNOT-22, 22-item sinonasal outcome test; LKES, Lund-Kennedy endoscopy scores; FVC, forced vital capacity; PEF, peak expiratory flow; FEV, forced expiratory volume; rhLPHN3 $\mathrm{Ab}$, recombinant human latrophilin 3 antibody.

USA) was used for analyzing NF- $\kappa \mathrm{B}$ activation using an assay of the photons produced (measured in relative light units).

DNA binding activity. Airway smooth muscle cells were isolated from pediatric asthma patients on week 0 and 16 . DNA binding activity was determined by DNA binding and antitrypanosomal activity as reported previously (21).

Outcome measurement. SNOT-22 and LKES tests were used for assessing the efficacy of salbutamol, montelukast and rhLPHN3 Ab treatments in children with pediatric asthma at the baseline and post-treatment at week 16. Clinical pediatric asthma scores were evaluated as descripted in previous studies $(22,23)$.

Lung function testing. Lung function tests, including the FEV percentage, FVC and PEF, were conducted using a Jaeger MasterScreen Pulmonary Function Testing system (Jaeger; BD Biosciences, Franklin Lakes, NJ, USA) to evaluate the tidal breathing flow volume at the baseline and post-treatment. The procedures were performed according to the manufacturer's instructions.

Efficacy and safety assessments. Subjective and objective outcome measurements were used to assess the efficacy of salbutamol, montelukast and rhLPHN3 Ab on children patients with pediatric asthma. In order to minimize bias, a single physician measured the scores at the preoperative baseline and post-treatment. Efficacy assessments, including the median percent reduction scores and response rate, were analyzed in children with pediatric asthma from baseline during the 16-week and double-blind period in the presence of rhLPHN3 Ab (12 mg/day). The safety assessments of the most frequent treatment-emergent adverse events were evaluated in all children with pediatric asthma who received the study drug.

ELISA for detection of plasma concentration. The levels of interleukin (IL)-10 (BMS614-2), IL-17 (39-8170-65), IL-4 (39-8041-65), MMP-9 (BMS2016-2), interferon- $\gamma$ (IFN- $\gamma$; BMS216TEN) and TGF- $\beta$ (BMS249-4TEN) in the serum of children patients with asthma were investigated using commercial ELISA kits (Thermo Fisher Scientific, Inc.), according to the manufacturer's protocols. Absorption was measured at $450 \mathrm{~nm}$ with an ELISA reader, and was subsequently converted to the concentrations of IL-10, IL-17, IL-4, MMP-9, IFN- $\gamma$ and TGF- $\beta$ (24).

Evaluation of toxicity. The median overall duration of treatment for dose-limiting toxicity (DLT) and maximum tolerated dose (MTD) was 16 weeks for rhLPHN3 Ab dosing cohorts $(1,6,12,24$ and $30 \mathrm{mg})$ and each group had 20 patients. Toxicity was graded using the National Cancer Institute Common Toxicity Criteria (version 3.0). DLT and MTD of rhLPHN3 Ab were evaluated by hypertension and proteinuria grade, as described previously (25).

Statistical analysis. All data are reported as the mean \pm standard error of the mean. Differences between mean values were assessed by Student's t-test for unpaired data. Comparisons of data between multiple groups were performed with analysis of variance. Responder rates and treatment-emergent adverse events were analyzed by $\chi^{2}$ test. $\mathrm{P}<0.05$ was considered as an indicator of statistically significant differences.

\section{Results}

Characteristics of patients with pediatric asthma. In total,342 patients with pediatric asthma were recruited into the present analysis. The characteristics of the children patients are summarized in Table I. Out of 342 patients, 134 received salbutamol, 108 received montelukast and 100 received rhLPHN3 Ab treatment. The number of male and female patients was approximately equal. In addition, the scores of asthma in children were analyzed by SNOT-22 and LKES determination in order to evaluate the extent of asthma at the baseline and following salbutamol, montelukast and rhLPHN3 $\mathrm{Ab}$ treatment. The patients did not receive any other medications during the treatment period.

Duration of treatment, DLT and MTD of rhLPHN3 Ab. The overall duration of salbutamol, montelukast and rhLPHN3 $\mathrm{Ab}$ treatments were identified as 16 weeks for all treatments. The various doses of rhLPHN3 Ab were 1, 6, 12, 24 and $30 \mathrm{mg}$, which were used to evaluate the optimal dosage. Data presented in Table II revealed that the DLT and MTD of rhLPHN3 Ab were 24 and $30 \mathrm{mg}$, respectively. Furthermore, analysis indicated that the common treatment-emergent adverse events of rhLPHN3 Ab treatment were hypertension, proteinuria, fatigue, hypertriglyceridemia, constipation and edema peripheral (Table II). Notably, the majority of patients with pediatric asthma required reduction of the drug dose due to cumulative toxicity following treatment with the MTD dose of rhLPHN3 Ab. Therefore, pediatric asthma patients 
Table II. Treatment-emergence adverse events of rhLPHN3 Ab after 16 weeks treatment.

\begin{tabular}{|c|c|c|c|c|}
\hline \multirow[b]{2}{*}{ Adverse event } & \multirow[b]{2}{*}{$\begin{array}{c}\text { Total } \\
(\mathrm{n}=100)\end{array}$} & \multicolumn{3}{|c|}{ Dose of rhLPHN3 Ab } \\
\hline & & $\begin{array}{c}1-6 \mathrm{mg} / \mathrm{day} \\
(\mathrm{n}=40)\end{array}$ & $\begin{array}{c}12-24 \mathrm{mg} / \text { day } \\
(\mathrm{n}=40)\end{array}$ & $\begin{array}{c}30 \mathrm{mg} / \text { day } \\
(\mathrm{n}=20)\end{array}$ \\
\hline Hypertension & 8 & 2 & 3 & 3 \\
\hline Proteinuria & 5 & 1 & 2 & 2 \\
\hline Fatigue & 3 & 0 & 1 & 2 \\
\hline Hypertriglyceridemia & 3 & 1 & 1 & 1 \\
\hline Constipation & 4 & 1 & 1 & 2 \\
\hline Edema peripheral & 4 & 1 & 1 & 2 \\
\hline
\end{tabular}

Treatment-emergent adverse events were analyzed by $\chi^{2}$ test. rhLPHN3 Ab, recombinant human latrophilin 3 antibody.

Table III. Hypertension and proteinuria grades after 16 weeks treatment with rhLPHN3 Ab.

\begin{tabular}{|c|c|c|c|c|}
\hline \multirow[b]{2}{*}{ Adverse event } & \multirow[b]{2}{*}{$\begin{array}{c}\text { Total } \\
(n=37)\end{array}$} & \multicolumn{3}{|c|}{ Dose of rhLPHN3 Ab } \\
\hline & & $\begin{array}{c}1-10 \mathrm{mg} / \text { day } \\
(\mathrm{n}=12)\end{array}$ & $\begin{array}{c}15 \mathrm{mg} / \mathrm{day} \\
(\mathrm{n}=15)\end{array}$ & $\begin{array}{c}20 \mathrm{mg} / \text { day } \\
(\mathrm{n}=10)\end{array}$ \\
\hline Hypertension & 8 & 2 & 3 & 3 \\
\hline Grade 1 & 4 & 1 & 2 & 1 \\
\hline Grade 2 & 2 & 0 & 1 & 1 \\
\hline Grade 3 & 2 & 1 & 0 & 1 \\
\hline Proteinuria & 5 & 1 & 2 & 2 \\
\hline Grade 1 & 2 & 0 & 1 & 1 \\
\hline Grade 2 & 2 & 1 & 1 & 0 \\
\hline Grade 3 & 1 & 0 & 0 & 1 \\
\hline
\end{tabular}

Treatment-emergent adverse events were analyzed by $\chi^{2}$ test. rhLPHN3 Ab, recombinant human latrophilin 3 antibody.

included in the present study received a dose of $12 \mathrm{mg} /$ day rhLPHN3 Ab. Following administration of the last dose of rhLPHN3 Ab (12 mg), it was observed that the most common treatment-emergent adverse events were hypertension and proteinuria ( $\geq 10 \%$ each; Table III). Among the total cohort of patients, all pediatric asthma patients completed the overall maintenance period of the phase I study $(n=100)$.

Efficacy of rhLPHN3 Ab treatment in patients with pediatric asthma. In order to investigate the efficacy of rhLPHN3 Ab treatment on the improvement of pediatric asthma, the therapeutic effects in 100 patients using the SNOT-22 and LKES tests. The onset frequency, duration of capillary bronchitis and asthma were compared among patients receiving treatments of salbutamol, montelukast and rhLPHN3 Ab. As shown in Fig. $1 \mathrm{~A}$, the present study data demonstrated that the onset frequency was significantly decreased in the three groups, while the outcomes in the rhLPHN3 Ab group were better as compared with the salbutamol and montelukast groups $(\mathrm{P}<0.01)$. The results shown in Fig. 1B revealed that the duration of capillary bronchitis was relieved and 63 patients completely recovered subsequent to rhLPHN3 Ab treatment. Meanwhile, the duration of asthma was decreased following treatment with salbutamol, montelukast and rhLPHN3 Ab (Fig. 1C). It was also observed that the number of days patients were awakened during the night was evidently decreased subsequent to 16 -week treatment in the three groups (Fig. 1D). These data suggest that rhLPHN3 $\mathrm{Ab}$ is more efficient compared with salbutamol and montelukast for the treatment of pediatric asthma.

Analysis of inflammatory factors in pediatric asthma patients following treatment with rhLPHN3 Ab. The levels of various inflammatory factors (IL-10, IL-17, IL-4, MMP-9, IFN- $\gamma$ and TGF- $\beta$ ) in the patients with pediatric asthma were analyzed in the present clinical study. As shown in Fig. 2A, the results demonstrated that IL-10 concentration was upregulated following treatment with salbutamol, montelukast and rhLPHN3 Ab.By contrast, the plasma concentration of IL-17 was decreased in all treatment groups, while IL-17 levels were significantly lower in the rhLPHN3 Ab group compared with salbutamol and montelukast groups $(\mathrm{P}<0.01$, Fig. 2B). In addition, rhLPHN3 Ab treatment downregulated MMP-9 plasma levels, which may contribute to inhibition of the inflammatory response (Fig. 2C). It was also observed 
A

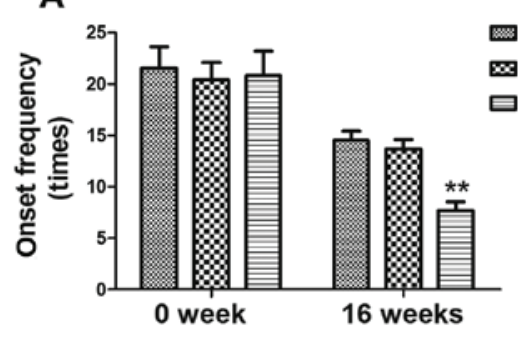

C

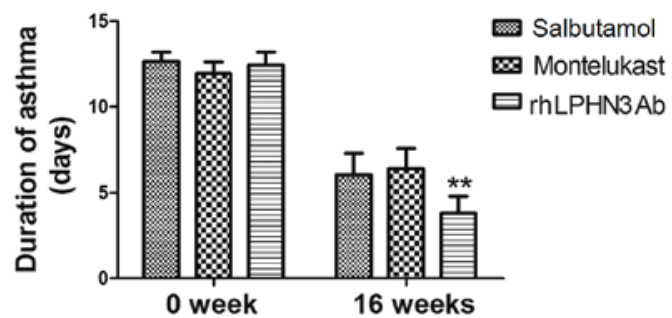

B

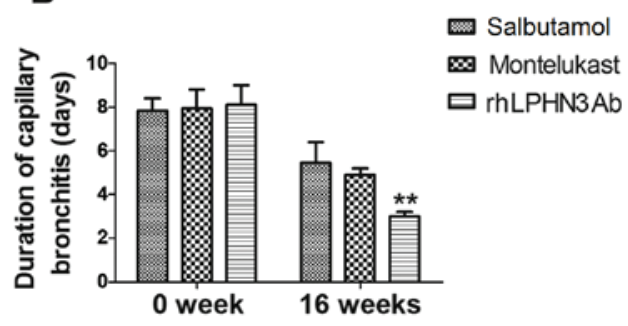

D

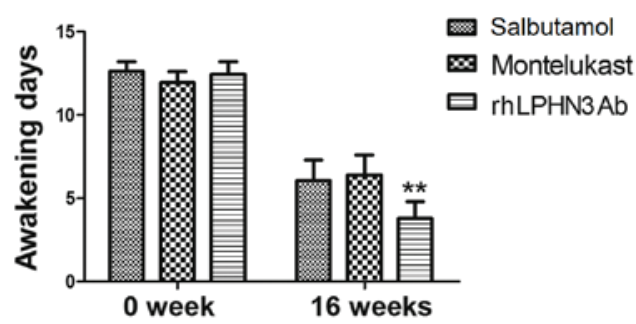

Figure 1. Efficacy of rhLPHN3 Ab treatment in patients with pediatric asthma. The (A) onset frequency, (B) duration of capillary bronchitis, (C) duration of asthma, and (D) number of the days patients were awakened during the night were evaluated prior to treatment ( 0 weeks) and following treatment (16 weeks). ${ }^{* * *} \mathrm{P}<0.01$ vs. salbutamol and montelukast. rhLPHN3 Ab, recombinant human latrophilin 3 antibody.
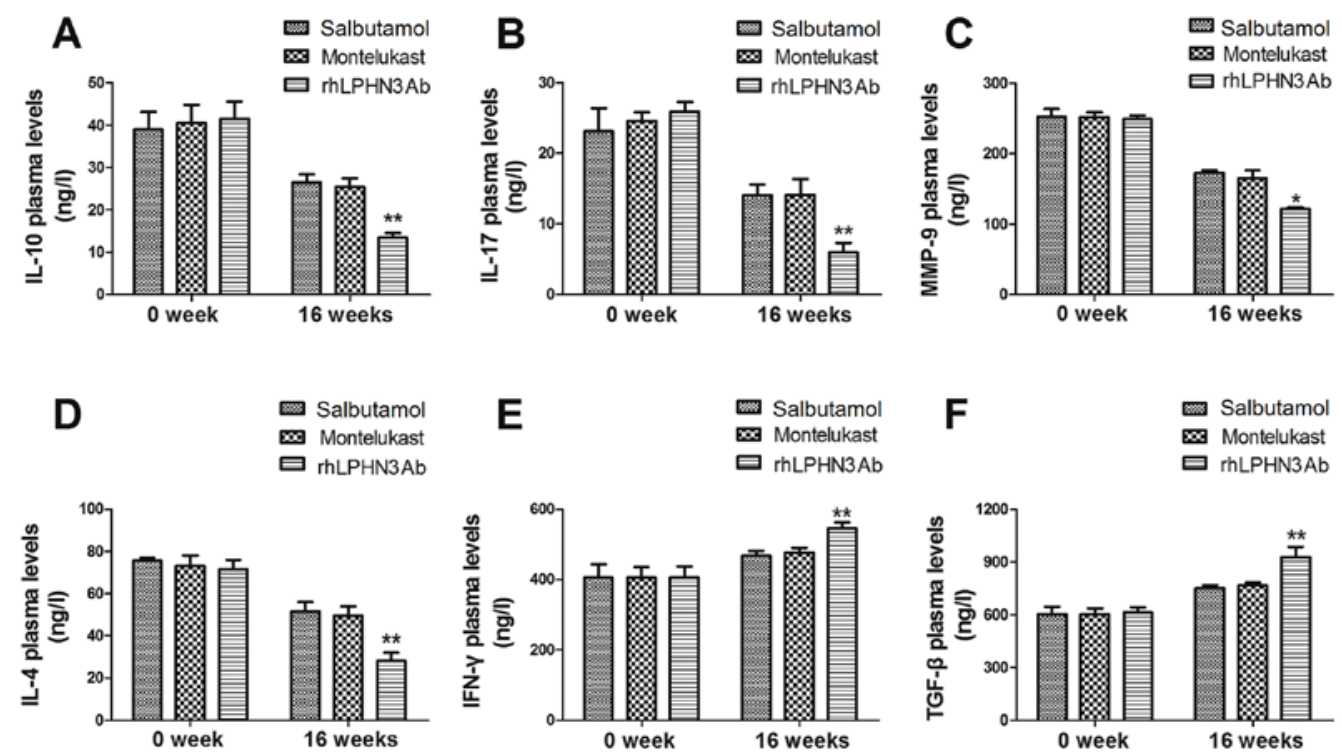

Figure 2. Analysis of alterations in inflammatory factor levels in patients with pediatric asthma following treatment with salbutamol, montelukast and rhLPHN3 Ab. (A) IL-10, (B) IL-17 and (C) MMP-9 plasma concentration levels were downregulated after treatment (16 weeks). (D) IL-4, (E) IFN- $\gamma$ and (F) TGF- $\beta$ plasma concentration levels were upregulated after treatment with salbutamol, montelukast and rhLPHN3 Ab. ${ }^{*}<0.05$ and ${ }^{* *} \mathrm{P}<0.01$ vs. salbutamol and montelukast. rhLPHN3 Ab, recombinant human latrophilin 3 antibody. IL, interleukin; MMP-9, matrix metallopeptidase-9; IFN- $\gamma$, interferon- $\gamma$; TGF- $\beta$, transforming growth factor- $\beta$.

that IL-4 plasma concentration levels were significantly downregulated in rhLPHN3 Ab group compared with the salbutamol and montelukast groups (Fig. 2D). Furthermore, it was observed that IFN- $\gamma$ and TGF- $\beta$ concentration levels were higher in rhLPHN3 Ab group compared with the salbutamol and montelukast groups (Fig. 2E and F). These observations indicated that the inflammatory factor levels in the children were improved following treatment with rhLPHN3 Ab.

Analysis of potential mechanism mediated by rhLPHN3 A bin airway smooth muscle cells. Previous studies have proposed numerous signaling pathways that participate in the development and progression of pediatric asthma $(26,27)$. In the present study, the rhLPHN3 Ab-mediated signaling pathway in airway smooth muscle cells was investigated. Initially, the E-selectin and MUC5AC expression levels in these cells were investigated. As shown in Fig. 3A-B, rhLPHN3 Ab treatment significantly decreased E-selectin and MUC5AC expression levels in the airway smooth muscle cells as compared with the salbutamol and montelukast groups. In addition, data revealed that rhLPHN3 $\mathrm{Ab}$ treatment markedly reduced the phosphorylation of PKA in the airway smooth muscle 
A

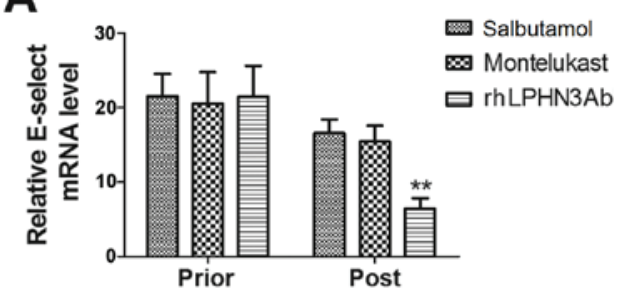

C
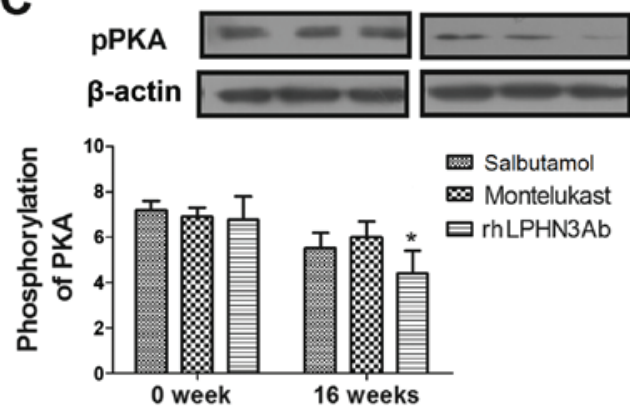

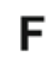

$\mathbf{F}$

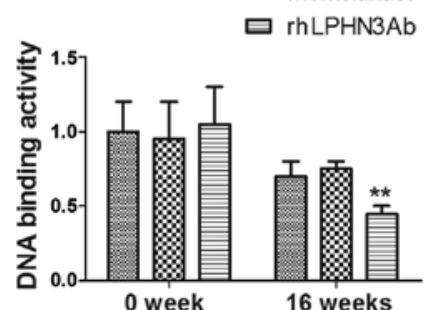

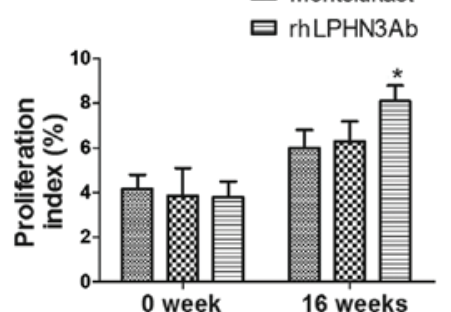
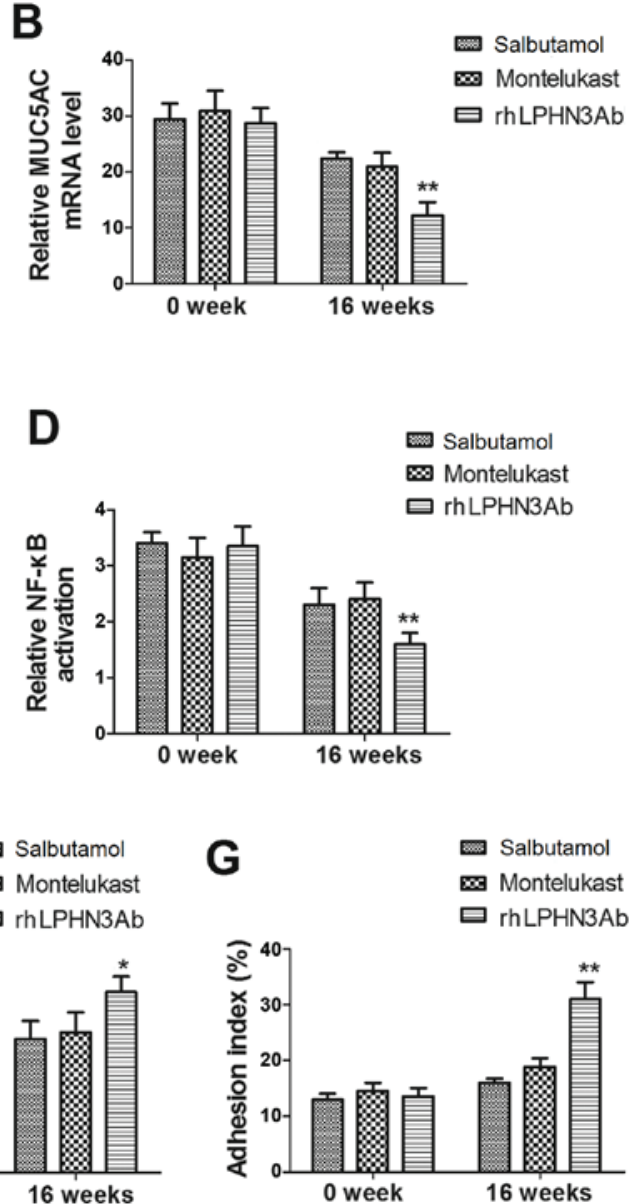

Figure 3. rhLPHN3 Ab treatment had a beneficial effect in pediatric asthma via NF-кB signaling pathway regulation. Relative mRNA expression levels of (A) E-selectin and (B) MUC5AC in the airway smooth muscle cells was determined by polymerase chain reaction. (C) Phosphorylation of PKA in the airway smooth muscle cells determined by western blot analysis. Analysis of the (D) NF-kB activation and (E) DNA binding activity, as well as alterations in the (F) proliferation and $(\mathrm{G})$ adhesion of airway smooth muscle cells prior to and following treatment. ${ }^{*} \mathrm{P}<0.05$ and ${ }^{* *} \mathrm{P}<0.01$ vs. salbutamol and montelukast rhLPHN3 Ab, recombinant human latrophilin 3 antibody; MUC5AC, mucin 5AC; PKA, protein kinase A; NF, nuclear factor;

cells compared with the other treatment agents (Fig. 3C). Furthermore, $\mathrm{NF}-\kappa \mathrm{B}$ activation and DNA binding activity were decreased in the cells following rhLPHN3 Ab treatment (Fig. 3D and E). rhLPHN3Ab also markedly improved the adhesion and proliferation of airway smooth muscle cells obtained from patients with pediatric asthma (Fig. 3F and G). These observations suggest that rhLPHN3 Ab treatment may improve pediatric asthma via the PKA-induced NF- $\kappa \mathrm{B}$ signaling pathway.

rhLPHN3Ab treatment improves the function of airway smooth muscle cells and lung contraction. The current study further analyzed the morphologic changes induced in airway smooth muscle cells after a 16-week treatment. As shown in Fig. 4A, rhLPHN3 Ab markedly inhibited airway mucus secretion when compared with that in the salbutamol and montelukast groups. It was also observed that the lung function of patients was improved following treatment with rhLPHN3 Ab, as determined by SNOT-22 and LKES testing (Fig. 4B and C).The results further revealed that rhLPHN3 Ab treatment markedly improved the contraction of the airways compared with the salbutamol and montelukast groups, as demonstrated by the FVC, PEF and FEV values (Fig. 4D-F). These results suggest that rhLPHN3 Ab contributes to the improvement of pediatric asthma by regulating the activity of the airway smooth muscle cells.

\section{Discussion}

According to previous studies, immune dysfunction and abnormal expression of inflammation factors are closely associated with capillary bronchial asthma, bronchitis and other infant asthmatic diseases (28-30). Notably, Li et al (31) have demonstrated that the PKA-dependent $\mathrm{NF}-\kappa \mathrm{B}$ signaling pathway is a novel target for drug action in asthma therapy. In addition, evidence indicated that latrophilin receptors are associated with heterogeneous behavioral disorder (32), which is also a novel target in asthma $(14,33)$. In the present study, the changes in inflammation factor levels and the mechanism underlying the rhLPHN3 Ab-mediated signaling pathway were analyzed in patients with pediatric asthma. The clinical outcomes revealed that rhLPHN3 Ab treatment decreased the levels of plasma pro-inflammatory factors, pulmonary pathological alterations, MUC5AC and E-selectin expression levels and mucus hyper-secretion in patients with pediatric asthma. In addition, data in the present analysis also revealed that rhLPHN3 Ab significantly facilitated the proliferation and adhesion of airway smooth 

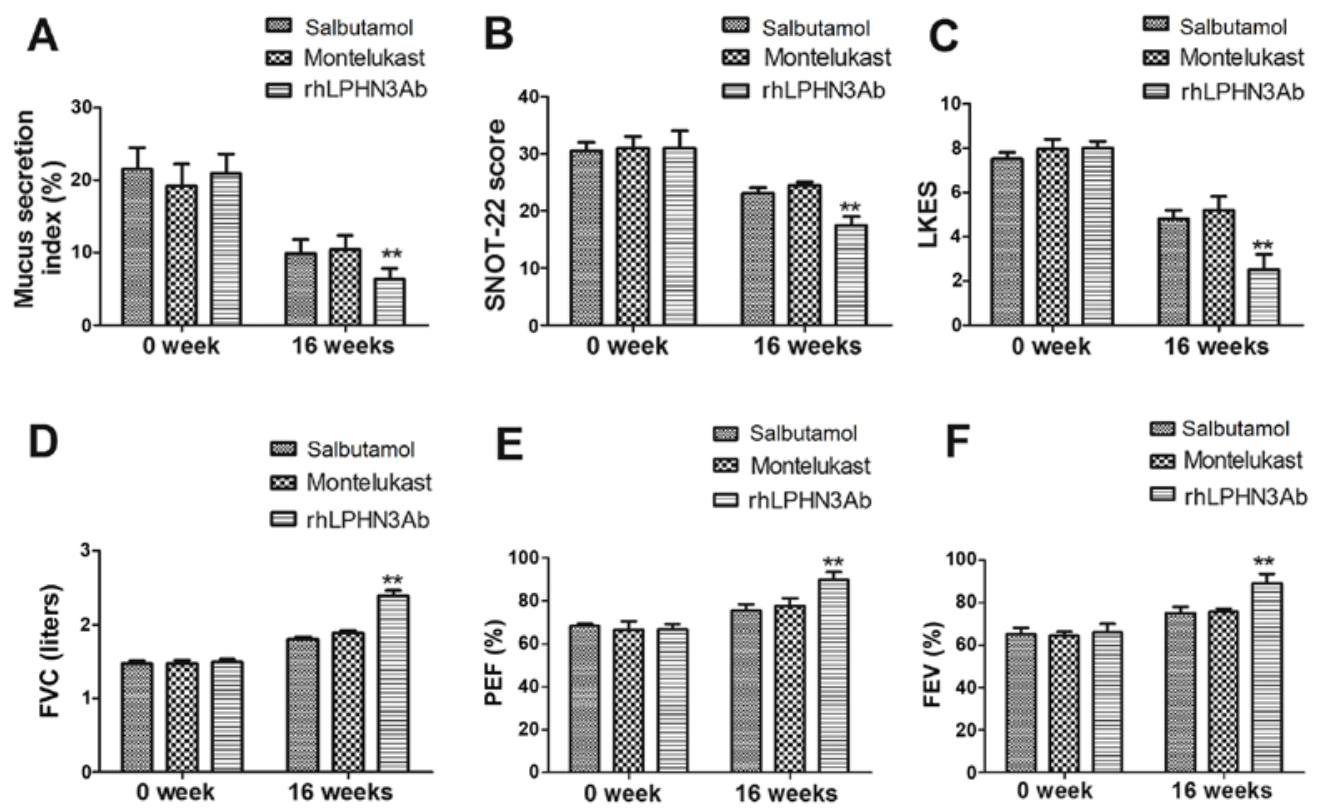

Figure 4. Analysis of functional recovery of lungs subsequent to rhLPHN3 Ab treatment. (A) Alterations in airway mucus secretion in patients with pediatric asthma are shown. Lung function after the treatment with rhLPHN3 Ab was determined by (B) SNOT-22 and (C) LKES examination. Contraction in the airway smooth muscles was analyzed by (D) FVC, (E) PEF and (F) FEV in patients with pediatric asthmafollowing rhLPHN3 Ab. ${ }^{* *} \mathrm{P}<0.01$ vs. salbutamol and montelukast. rhLPHN3 Ab, recombinant human latrophilin 3 antibody; SNOT-22, 22-item sinonasal outcome test; LKES, Lund-Kennedy endoscopy scores; FVC, forced vital capacity; PEF, peak expiratory flow; FEV, forced expiratory volume.

muscle cells in patients with pediatric asthma after 16-week treatment. Furthermore, it has been suggested that rhLPHN3 $\mathrm{Ab}$ decreased $\mathrm{NF}-\kappa \mathrm{Blevels}$ and improved the contraction of the airways through regulation of the PKA-mediated $\mathrm{NF}-\kappa \mathrm{B}$ signaling pathway. These findings indicate that rhLPHN3 $\mathrm{Ab}$ may be an efficient agent for the treatment of pediatric asthma.

Currently, pediatric asthma presents the characteristics of chronic inflammatory responses and systolic dysfunction of the airway, in which marked changes in airway smooth muscle cell contraction are observed. In a recent study, a systematically review revealed the associations between inflammatory responses and asthma severity in pediatric asthma, which indicated that IFN- $\gamma$, IL-10 and IL-17 may serve as prognostic indicators of pediatric asthma (34). In addition, various strategies targeting inflammatory responses to improve airway remodeling in asthma physiopathology have been investigated, and the results of these studies support the hypothesis that modulating the allergic inflammation improved asthma physiopathology in patients with asthma in animals model and clinical trials (35-38). Furthermore, previous reports have indicated that the pathogenesis of airway inflammation in asthma patients may be associated with the normal function and maintenance of the airway smooth muscle cells (39-41). To investigate the therapeutic effects of rhLPHN3 Ab in the treatment of pediatric asthma, the current study analyzed the cytokine expression levels in the plasma of patients. It was observed that rhLPHN3 Ab significantly inhibited IL-17, MMP-9 and IL-10 levels, while it enhanced IL-4, IFN- $\gamma$ and TGF- $\beta$ expression levels in the peripheral blood. This inhibitory effect may contribute to the morphological changes of airway smooth muscle cells. It was indicated that 16 -week rhLPHN3 Ab treatment improved BMI, SNOT-22, LKES, FVC, PEF and FEV.
Clinical manifestations of asthma include the first onset of capillary bronchitis, typical bronchial asthma, and chronic inflammation of the airway, which have been regarded as evaluation criteria for patients with asthma (42-44). In addition, studies have indicated that the number of times patients were awakened by asthma during the night is also an important factor that evaluates the efficacy of the childhood asthma treatment $(45,46)$. Furthermore, contraction of the airways is another factor to evaluate the extent of capillary bronchitis, which may be an early signal of bronchial asthma in children $(47,48)$. In the current study, the efficacy of rhLPHN3 $\mathrm{Ab}$ on the onset frequency, duration of capillary bronchitis, asthma and times awakened was investigated and compared with the effects of salbutamol and montelukast serving as the controls. The findings revealed that rhLPHN3 Ab evidently improved the clinical manifestations in patients with pediatric asthma.

Notably, it has been reported that PKA-mediated NF- $\kappa \mathrm{B}$ signaling pathway may be associated with the progression of pediatric asthma $(49,50)$. In addition, previous studies demonstrated that liraglutide possesses an anti-inflammatory potential through inactivation of TNF- $\alpha$ expression and activation of $\mathrm{NF}-\kappa \mathrm{B}$ signaling pathway in the progression of pediatric asthma $(51,52)$. Furthermore, a previous report indicated that inhibition of NF- $\mathrm{NB}$ signaling pathway led to the amelioration of inflammation and airway hyperresponsiveness in a mouse asthma model (53). Similarly, the current study observed that rhLPHN3 Ab inhibited the inflammatory responses through PKA-mediated $\mathrm{NF}-\kappa \mathrm{B}$ signaling pathway, which may contribute to the recovery of patients with pediatric asthma.

In conclusion, the clinical outcomes of patients included in the present study suggested that clinical treatment with rhLPHN3 Ab exerted various beneficial effects on the secretion 
of inflammatory mediators in pediatric asthma, which contributes to the recovery of typical bronchial asthma, and chronic inflammation of the airway in patients with pediatric asthma. These findings contribute to better understand the immunologic mechanism underlying the rhLPHN3 Ab-mediated treatment for pediatric asthma.

\section{References}

1. Rubin BK: Asthma 2015: The year in review. Respir Care 61: $556-559,2016$.

2. Rodriguez-Villamizar LA, Berney C, Villa-Roel C, Ospina MB, Osornio-Vargas A and Rowe BH: The role of socioeconomic position as an effect-modifier of the association between outdoor air pollution and children's asthma exacerbations: An equity-focused systematic review. Rev Environ Health 31: 297-309, 2016.

3. Rodrigo GJ and Plaza V: Once-daily fluticasone furoate and vilanterol for adolescents and adults with symptomatic asthma: A systematic review with meta-analysis. Ann Allergy Asthma Immunol 116: 565-570, 2016.

4. Pols DH, Wartna JB, Moed H, van Alphen EI, Bohnen AM and Bindels PJ: Atopic dermatitis, asthma and allergic rhinitis in general practice and the open population: A systematic Review. Scand J Prim Health Care 34: 143-150, 2016

5. Paone G, Leone V, Conti V, De Marchis L, Ialleni E, Graziani C, Salducci M, Ramaccia M and Munafò G: Blood and sputum biomarkers in COPD and asthma: A review. European Rev Med Pharmacol Sci 20: 698-708, 2016.

6. Nwaru BI, McCleary N, Erkkola M, Kaila M, Virtanen SM and Sheikh A: Assisted reproductive technology and risk of asthma and allergy in the offspring: Protocol for a systematic review and meta-analysis. BMJ Open 6: e010697, 2016.

7. Oh S, Ji H, Barzman D, Lin PI and Hutton J: Pediatric asthma and autism-genomic perspectives. Clin Transl Med 4: 37, 2015

8. Wu DJ, Hipolito E, Bilderback A, Okelo SO and Garro A: Predicting future emergency department visits and hospitalizations for asthma using the pediatric asthma control and communication instrument-emergency department version (PACCI-ED). J Asthma 53: 387-391, 2016.

9. Doymaz S, Schneider J and Sagy M: Early administration of terbutaline in severe pediatric asthma may reduce incidence of acute respiratory failure. Ann Allergy Asthma Immunol 112: 207-210, 2014.

10. Myers TR: Pediatric asthma epidemiology: Incidence, morbidity, and mortality. Respir Care Clin N Am 6: 1-14, 2000.

11. Doymaz S and Schneider J: Safety of terbutaline for treatment of acute severe pediatric asthma. Pediatr Emerg Care: Mar 8, 2016 (Epub ahead of print).

12. Booster GD, Oland AA and Bender BG: Psychosocial factors in severe pediatric asthma. Immunol Allergy Clin North Am 36: 449-460, 2016.

13. Idris IB, Ghazi HF, Zhie KH, Khairuman KA, Yahya SK, Abd Zaim FA, Nam CW, Abdul Rasid HZ and Isa ZM: Environmental air pollutants as risk factors for asthma among children seen in pediatric clinics in UKMMC, Kualalumpur. Annals Glob Health 82: 202-208, 2016.

14. Faiz A, Donovan C, Nieuwenhuis MA, van den Berge M, Postma DS, Yao S, Park CY, Hirsch R, Fredberg JJ, Tjin G, et al Latrophilin receptors: Novel bronchodilator targets in asthma. Thorax 72: 84-82, 2017

15. Volynski KE, Silva JP, Lelianova VG, Atiqur Rahman M, Hopkins $\mathrm{C}$ and Ushkaryov YA: Latrophilin fragments behave as independent proteins that associate and signal on binding of LTX(N4C). EMBO J 23: 4423-4433, 2004.

16. Gao GX, Li QM and Shen HH: Effect of astragali-cordyceps mixtura on TGF-beta/Smad signal pathway in the lung of asthma airway remodeling. J Ethnopharmacol 125: 68-74, 2009.

17. Li CC, Lin L, Wang XL, Guan XJ, Su MS, Xiang QW, Han H, Zhang WX and Li MR: Role of c-Jun N-terminal kinase signal transduction pathway in the course of airway remodeling of asthma rat. Zhonghua er ke za zhi. Zhonghua Er Ke Za Zhi 46: 535-539, 2008 (In Chinese).

18. Xie M, Liu XS, Xu YJ, Zhang ZX, Bai J, Ni W and Chen SX: Role of the extracellular signal-regulated kinase $1 / 2$ signaling pathway in regulating the secretion of bronchial smooth muscle cells in a rat model of chronic asthma. Chin Med J (Engl) 121: 73-77, 2008.
19. Caminha GP, Melo Junior JT, Hopkins C, Pizzichini E and Pizzichini MM: SNOT-22: Psychometric properties and cross-cultural adaptation into the Portuguese language spoken in Brazil. Braz J Otorhinolaryngol 78: 34-39, 2012.

20. Livak KJ and Schmittgen TD: Analysis of relative gene expression data using real-time quantitative PCR and the 2(-Delta Delta C(T)) methods. Methods 25: 402-408, 2001.

21. Janockova J, Zilecka E, Kasparkova J, Brabec V, Soukup O, Kuca K and Kozurkova M: Assessment of DNA-binding affinity of cholinesterase reactivators and electrophoretic determination of their effect on topoisomerase I and II activity. Mol Biosyst 12: 2910-2920, 2016.

22. Rudmik L, Soler ZM, Mace JC, DeConde AS, Schlosser RJ and Smith TL: Using preoperative SNOT-22 score to inform patient decision for Endoscopic sinus surgery. Laryngoscope 125: 1517-1522, 2015.

23. Huang J, Chen Y, Long Z, Zhou X and Shu J: Clinical efficacy of tiotropium in children with asthma. Pak J Med Sci 32: 462-465, 2016.

24. Diaz I and Mateu E: Use of ELISPOT and ELISA to evaluate IFN-gamma, IL-10 and IL-4 responses in conventional pigs. Vet Immunol Immunopathol 106: 107-112, 2005.

25. Mehravi B, Alizadeh AM, Khodayari S, Khodayari H, Ashtari K, Mohseni M, Anaraki NI, Dana EA, Safari S and Amanlou M: Acute toxicity evaluation of glycosylated Gd3+-based silica nanoprobe. Mol Imaging Biol 19: 522-530, 2017.

26. Kim SP, Lee SJ, Nam SH and Friedman M: Elm Tree (Ulmus parvifolia) Bark Bioprocessed with Mycelia of Shiitake (Lentinus edodes) Mushrooms in Liquid Culture: Composition and mechanism of protection against allergic asthma in mice. J Agric Food Chem 64: 773-784, 2016.

27. Bardin P, Kanniess F, Gauvreau G, Bredenbroker D and Rabe KF: Roflumilast for asthma: Efficacy findings in mechanism of action studies. Pulm Pharmacol Ther 35 (Suppl): S4-S10, 2015.

28. Johnathan M, Gan SH, Ezumi MF, Faezahtul AH and Nurul AA: Phytochemical profiles and inhibitory effects of Tiger Milk mushroom (Lignosus rhinocerus) extract on ovalbumin-induced airway inflammation in a rodent model of asthma. BMC Complement Altern Med 16: 167, 2016.

29. de Araujo CC, Marques PS, Silva JD, Samary CS, da Silva AL, Henriques I, Antunes MA, de Oliveira MV, Goldenberg RC, Morales MM, et al: Regular and moderate aerobic training before allergic asthma induction reduces lung inflammation and remodeling. Scand J Med Sci Sports 26: 1360-1372, 2016.

30. Phillips JE, Renteria L, Burns L, Harris P, Peng R, Bauer CM, Laine D and Stevenson CS: Btk inhibitor RN983 delivered by dry powder nose-only aerosol inhalation inhibits bronchoconstriction and pulmonary inflammation in the ovalbumin allergic mouse model of asthma. J Aerosol Med Pulm Drug Deliv 29: 233-241, 2016.

31. Li Z, Zheng J, Zhang N and Li C: Berberine improves airway inflammation and inhibits NF- $\kappa \mathrm{B}$ signaling pathway in an ovalbumin-induced rat model of asthma. J Asthma 53: 999-1005, 2016.

32. Choudhry Z, Sengupta SM, Grizenko N, Fortier ME, Thakur GA, Bellingham J and Joober R: LPHN3 and attention-deficit/hyperactivity disorder: Interaction with maternal stress during pregnancy. J Child Psychol Psychiatry 53: 892-902, 2012.

33. Tobaben S, Sudhof TC and Stahl B: Genetic analysis of alpha-latrotoxin receptors reveals functional interdependence of CIRL/latrophilin 1 and neurexin 1 alpha. J Biol Chem 277: 6359-6365, 2002.

34. Vanders RL, Gibson PG, Wark PA and Murphy VE: Alterations in inflammatory, antiviral and regulatory cytokine responses in peripheral blood mononuclear cells from pregnant women with asthma. Respirology 18: 827-833, 2013.

35. Mauffray M, Domingues O, Hentges F, Zimmer J, Hanau D and Michel T: Neurturin influences inflammatory responses and airway remodeling in different mouse asthma models. J Immunol 194: 1423-1433, 2015.

36. Vanoirbeek JA, De Vooght V, Nemery B and Hoet PH: Multiple challenges in a mouse model of chemical-induced asthma lead to tolerance: Ventilatory and inflammatory responses are blunted, immunologic humoral responses are not. Toxicology 257: 144-152, 2009.

37. Lim Y, Vasu VT, Valacchi G, Leonard S, Aung HH, Schock BC, Kenyon NJ, Li CS, Traber MG and Cross CE: Severe vitamin E deficiency modulates airway allergic inflammatory responses in the murine asthma model. Free Radical Res 42: 387-396, 2008. 
38. Bhandari V, Choo-Wing R, Chapoval SP, Lee CG, Tang C, Kim YK, Ma B, Baluk P, Lin MI and McDonald DM: Essential role of nitric oxide in VEGF-induced, asthma-like angiogenic, inflammatory, mucus, and physiologic responses in the lung. Proc Natl Acad Sci USA 103: 11021-11026, 2006.

39. Gaga M, Zervas E and Loukides S: The usefulness of inflammatory markers in monitoring treatment responses in asthma. Clin Exp Allergy 33: 855-858, 2003.

40. Boulay ME and Boulet LP: Lower airway inflammatory responses to repeated very-low-dose allergen challenge in allergic rhinitis and asthma. Clin Exp Allergy 32: 1441-1447, 2002.

41. Foster PS, Ming Y, Matthei KI, Young IG, Temelkovski J and Kumar RK: Dissociation of inflammatory and epithelial responses in a murine model of chronic asthma. Lab Invest 80: 655-662, 2000

42. Provotorov VM, Budnevsky AV and Filatova YI: Clinical manifestations of asthma during combination therapy using ceruloplasmin. Ter Arkh 88: 36-39, 2016 (In Russian).

43. Hartmann K, Escribano L, Grattan C, Brockow K, Carter MC, Alvarez-Twose I, Matito A, Broesby-Olsen S, Siebenhaar F, Lange $\mathrm{M}$, et al: Cutaneous manifestations in patients with mastocytosis: Consensus report of the European Competence Network on Mastocytosis; the American Academy of Allergy, Asthma \& Immunology; and the European Academy of Allergology and Clinical Immunology. J Allergy Clin Immunol 137: 35-45, 2016

44. Ghaffari J, Farid Hossiani R, Khalilian A, Nahanmoghadam N, Salehifar E and Rafatpanah H: Vitamin e supplementation, lung functions and clinical manifestations in children with moderate asthma: A randomized double blind placebo-controlled trial. Iran J Allergy Asthma Immunol 13: 98-103, 2014.

45. García-Martín E, García-Menaya J, Sánchez B, Martínez C, Rosendo R and Agúndez JA: Polymorphisms of histaminemetabolizing enzymes and clinical manifestations of asthma and allergic rhinitis. Clin Exp Allergy 37: 1175-1182, 2007.
46. Kim TB, Kim YK, Chang YS, Kim SH, Hong SC, Jee YK, Cho SH, Min KU and Kim YY: Association between sensitization to outdoor spider mites and clinical manifestations of asthma and rhinitis in the general population of adults. J Korean Med Sci 21: 247-252, 2006.

47. Araujo MI and de Carvalho EM: Human schistosomiasis decreases immune responses to allergens and clinical manifestations of asthma. Chem Immunol Allergy 90: 29-44, 2006.

48. Khamidova ZN: Clinical manifestations and a course of bronchial asthma complicated by gastroduodenal pathology. Probl Tuberk: 44-45, 2002 (In Russian).

49. Zhou Y, Wang GF, Yang L, Liu F, Kang JQ, Wang RL, Gu W and Wang CY: Treatment with 1,25(OH)2D3 induced HDAC2 expression and reduced NF- $\kappa \mathrm{B}$ p65 expression in a rat model of OVA-induced asthma. Braz J Med Biol Res 48: 654-664, 2015.

50. Pan $\mathrm{C}$ and Dong Z: Antiasthmatic Effects of Eugenol in a Mouse Model of Allergic Asthma by Regulation of Vitamin D3 Upregulated Protein 1/NF-кB Pathway. Inflammation 38: 1385-1393, 2015

51. Garcia-Garcia FJ, Mullol J, Perez-Gonzalez M, Pujols L, Alobid I, Roca-Ferrer J, Picado C: Signal transduction pathways (MAPKs, NF- $\kappa \mathrm{B}$, and $\mathrm{C} / \mathrm{EBP}$ ) regulating $\mathrm{COX}-2$ expression in nasal fibroblasts from asthma patients with aspirin intolerance. PLoS One 7: e51281, 2012.

52. Shimizu K, Konno S, Ozaki M, Umezawa K, Yamashita K, Todo S and Nishimura M: Dehydroxymethylepoxyquinomicin (DHMEQ), a novel NF-kappaB inhibitor, inhibits allergic inflammation and airway remodelling in murine models of asthma. Clin Exp Allergy 42: 1273-1281, 2012.

53. Lim JC, Goh FY, Sagineedu SR, Yong AC, Sidik SM, Lajis NH, Wong WS and Stanslas J: A semisynthetic diterpenoid lactone inhibits NF- $\mathrm{KB}$ signalling to ameliorate inflammation and airway hyperresponsiveness in a mouse asthma model. Toxicol Appl Pharmacol 302: 10-22, 2016. 